\title{
Factors Influencing the Progression and Direction of Scoliosis in Children with Neurological Disorders
}

\author{
Yeun-Jie Yoo ${ }^{1,+} \mathbb{D}^{\text {, Jung-Geun Park }}{ }^{1,+} \oplus$, Leechan Jo ${ }^{1}$, Youngdeok Hwang ${ }^{2}$, Mi-Jeong Yoon ${ }^{1}$, Joon-Sung Kim ${ }^{1}$, \\ Seonghoon Lim ${ }^{1}$ (1) and Bo-Young Hong $1, * \mathbb{C}$
}

1 Department of Rehabilitation Medicine, St. Vincent's Hospital, College of Medicine, The Catholic University of Korea, Seoul 16247, Korea; yeunjie@catholic.ac.kr (Y.-J.Y.); jgp0123@naver.com (J.-G.P.); joychan85@hotmail.com (L.J.); allogen@naver.com (M.-J.Y.); svpmr@chol.com (J.-S.K.); limseonghoon@gmail.com (S.L.)

2 Paul H. Chook Department of Information Systems and Statistics, Baruch College, City University of New York, New York, NY 10010, USA; youngdeok.hwang@baruch.cuny.edu

* Correspondence: byhong@songeui.ac.kr; Tel.: +82-31-249-7650

+ These authors contributed equally to this work.

check for updates

Citation: Yoo, Y.-J.; Park, J.-G.; Jo, L.; Hwang, Y.; Yoon, M.-J.; Kim, J.-S.; Lim, S.; Hong, B.-Y. Factors Influencing the Progression and Direction of Scoliosis in Children with Neurological Disorders. Children 2022, 9, 81. https://doi.org/ 10.3390/children 9010081

Academic Editor: Angelo

Gabriele Aulisa

Received: 22 November 2021

Accepted: 4 January 2022

Published: 6 January 2022

Publisher's Note: MDPI stays neutral with regard to jurisdictional claims in published maps and institutional affiliations.

Copyright: (C) 2022 by the authors. Licensee MDPI, Basel, Switzerland. This article is an open access article distributed under the terms and conditions of the Creative Commons Attribution (CC BY) license (https:// creativecommons.org/licenses/by/ $4.0 /)$.

\begin{abstract}
Background: scoliosis is highly prevalent in children with neurological disorders, however, studies predicting the progression and affecting the direction of scoliosis have been insufficient. We investigated the factors associated with the progression and direction of scoliosis in children with neurological disorders. (2) Method: retrospectively, 518 whole spine radiographs from 116 patients were used for analysis. Factors affecting the progression of scoliosis over time were analyzed using linear mixed-effects model. Factors associated with the apex direction of the scoliosis were analyzed. (3) Results: pelvic obliquity $(\mathrm{PO}) \geq 2.5^{\circ}$, gross motor function classification system level $\mathrm{V}$, vertebral rotation, and female sex significantly affect the progression of scoliosis $(p=0.04,<0.001,<0.001,0.005$, respectively). The higher side of $\mathrm{PO}$ and the apex side of scoliosis were interrelated $\left(\chi^{2}=14.58\right.$, $p<0.001$ ), but the asymmetrical neurological upper extremity involvement was not. (4) Conclusions: severely impaired gross motor function, PO, vertebral rotation, and female sex were significantly related to the progression of scoliosis. The higher side of PO was opposite to the apex side of scoliosis. By identifying the factors that influence the progression of scoliosis, patients at high risk could be more actively intervened to minimize the severe complications.
\end{abstract}

Keywords: scoliosis; children with neurological disorders; pelvic obliquity; GMFCS

\section{Introduction}

Scoliosis is defined as a structural alteration of the spine, in which the coronal plane curvature of the spine is greater than $10^{\circ}$. It is known that $25-74 \%$ of patients with cerebral palsy (CP) and 48-93\% of patients with Duchenne muscular dystrophy have scoliosis [1]. In a previous study [2] of CP patients with an average follow-up period of 16.5 years, the mean age of onset of scoliosis was 6.6 years, and about $50 \%$ of patients developed before six years of age. In this study, remeasurement after age 20 showed that $32.5 \%$ of patients had a scoliosis progression greater than $10^{\circ}$. This rapid progression of scoliosis has drawn attention to factors influencing the progression of scoliosis in children with neurological disorders, defined as disorders that involve central and peripheral nervous system.

Despite the various problems such as difficulty in maintaining seating and standing postures, pain, skin integrity, and cardiopulmonary dysfunction caused by scoliosis in these patients, the factors that predict scoliosis progression and determine the direction of the apex of scoliosis have been inconclusive. A systematic review in children with severe $\mathrm{CP}$ in 2010 found no definite evidence of an association between a few variables such as age, type of $\mathrm{CP}$, location of a scoliosis curve, pelvic obliquity (PO), hip dislocation, and progression of scoliosis [3]. In 2011, Gu et al. analyzed 110 patients with non-ambulatory spastic 
tetraplegic $\mathrm{CP}$ and found that Cobb angle greater than $40^{\circ}$ by age 12 was a significant predictor of scoliosis progression [4]. In 2018, Yoshida et al. investigated the natural history of scoliosis in 113 patients with CP and found the risk factors for progression of scoliosis were hip joint displacement, early onset of scoliosis, and Cobb angle of $30^{\circ}$ before the age of 10 [2].

Few previous researchers investigated the factors determining the apex side of scoliosis. Hägglund et al. [5] analyzed 79 patients with $\mathrm{CP}$ with a $\mathrm{PO}$ greater than $5^{\circ}$, suggested associations between the convexity of the scoliotic curve and the higher side of the PO, reduced range of hip abduction, and higher migration percentage of the hip displacement. Furthermore, Porter et al. [6] suggested a significant association between the direction of the apex of scoliosis and the windswept hip deformity. However, to the best of our knowledge, clinical factors such as hand dominance or asymmetric neurological upper extremity involvement have not been investigated as possible associative factors for the direction of the scoliotic curve.

The primary aim of this study is to determine various clinical and radiological factors that affect the progression of scoliosis in children with neurological disorders. The secondary aim is to identify the direction of scoliosis and its relationship to PO, asymmetric upper extremity function, and handedness.

\section{Materials and Methods}

\subsection{Study Design and Participants}

A retrospective observational study was conducted in children or adolescents from the department of rehabilitation medicine at St. Vincent's hospital between January 2005 and December 2020. A pediatric physiatrist verified the diagnosis of a neurological condition. Among them, patients under 20 years of age with scoliosis were confirmed on the first $\mathrm{X}$-ray, and who had taken anteroposterior (AP) and lateral whole spine radiographs at least 3 times during the follow-up period were recruited. Of the 137 selected subjects, 17 subjects without neurological disorders such as juvenile idiopathic scoliosis were excluded. Overall, 120 subjects and 527 radiographs were taken for measurement. Among the selected X-rays, four images from two subjects were unmeasurable due to pacemaker and brace. Three images from one subject were excluded due to screw fixation of the spine, and two images from one subject were excluded due to poor resolution. Finally, 116 patients were included, and 518 adequate longitudinal scoliosis radiographs were available for analysis. Cobb angle, PO, lumbar lordosis, and vertebral rotation were measured by two physiatrists (J.P. and L.J.). Gross motor function, sex, seizure history, asymmetricity of upper extremities, and handedness were reviewed based on medical charts. Gross motor function was measured with the gross motor function classification system (GMFCS), with levels from I (independent self-ambulation) to $\mathrm{V}$ (total dependent mobility, incomplete head control), at the initial evaluation [7]. The asymmetric neurological function of upper extremities was defined as the difference of one or more grades of motor power or spasticity between the right and left sides of upper extremities in terms of manual muscle test or modified Ashworth scale. The handedness was determined to be mainly used side for eating, reaching, grasping, and writing. It was classified as 'unknown' when it was difficult to determine the degree of upper extremity function or handedness through chart review.

\subsection{Measurement Parameters}

\subsubsection{Scoliosis}

Scoliosis was measured by Cobb's method, the angle between the superior end plate of the uppermost vertebral body and the inferior end plate of the lowermost vertebral body in scoliosis curvature in the AP radiographs (Figure 1A) [8]. The coronal direction of scoliosis was determined by the apex, defined as the farthest vertebrae from the central sacral vertical line, a vertical line perpendicular to the line across the top of the iliac crests [9]. Thus, the direction of scoliosis curve was determined by the direction of the apex. 


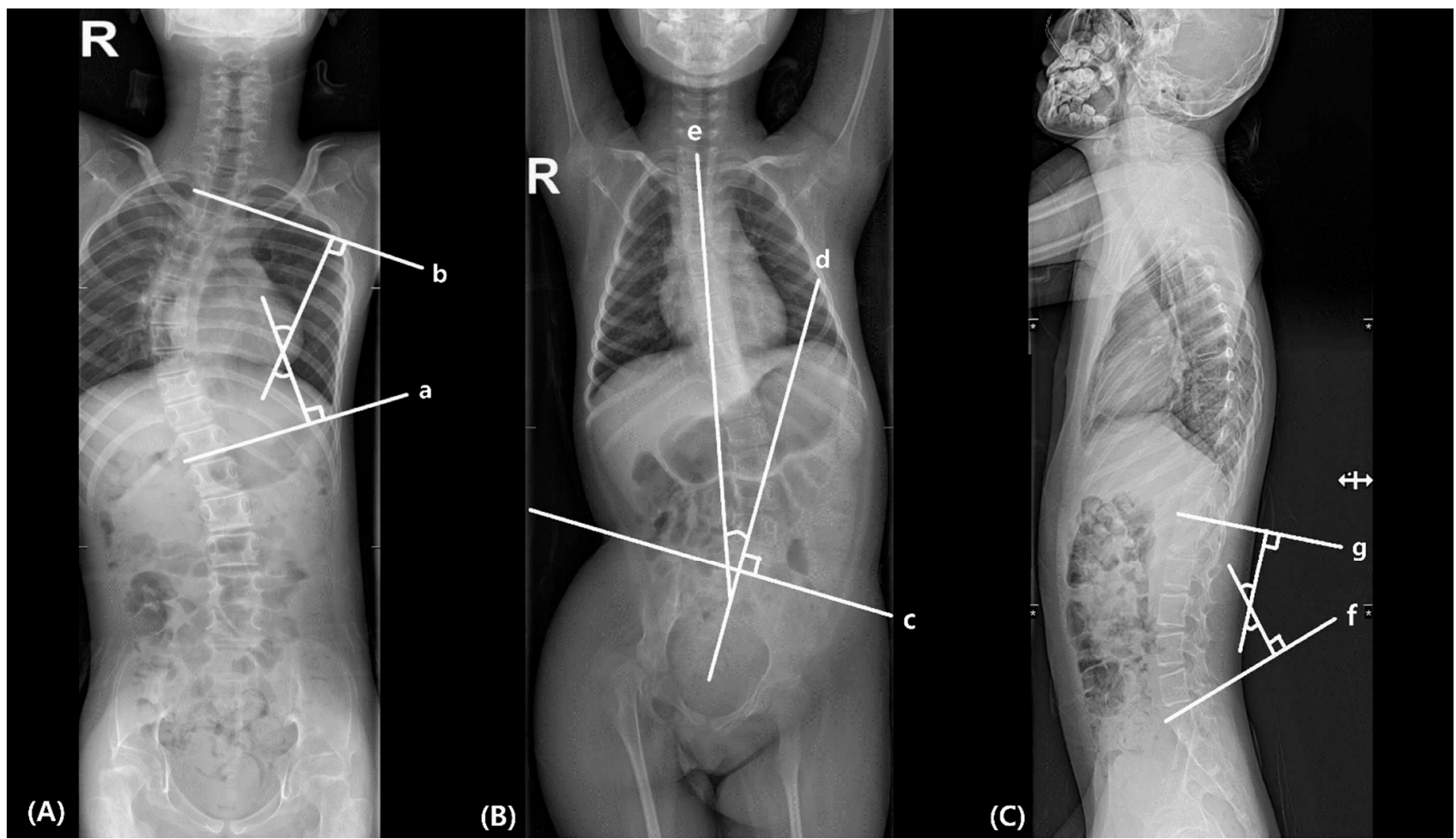

Figure 1. Measurement of (A) scoliosis, (B) pelvic obliquity and (C) lumbar lordosis. (a) The inferior endplate of the lowermost vertebral body in scoliosis curvature; (b) the superior end plate of the uppermost vertebral body in scoliosis curvature; (c) line connecting the bilateral iliac crests; (d) perpendicular line to the line connecting the bilateral iliac crests; (e) line between the center of T1 to S1 vertebral bodies; (f) S1 superior endplate line; (g) T12 inferior endplate line.

\subsubsection{Pelvic Obliquity (PO)}

PO was measured with the Maloney method, defined as the angle between the line perpendicular to the line connecting the bilateral iliac crests and the line between the center of $\mathrm{T} 1$ to $\mathrm{S} 1$ vertebral bodies in the AP radiographs (Figure 1B) [10]. The coronal direction of the $\mathrm{PO}$ was determined by the relationship between the two lines above. $\mathrm{PO}$ was also measured related to the presence of scoliosis.

\subsubsection{Lumbar Lordosis}

Lumbar lordosis was measured in the lateral radiographs by Cobb's method, angle between S1 superior end plate and T12 inferior end plate (Figure 1C) [11].

\subsubsection{Vertebral Rotation}

All AP radiographs were assessed vertebral rotational deformity by Nash-Moe method, defined as the percentage displacement of the convex pedicle in relation to the vertebral body width [12].

\subsection{Statistical Methods}

Descriptive analysis was used for all variables, including median and interquartile range for continuous data and percentages for categorical data. Inter-rater reliability of radiographic indices was assessed by interclass correlation coefficients (ICCs) estimates, and their $95 \%$ confident intervals $(\mathrm{CI})$ based on a mean-rating $(\mathrm{k}=2)$, absolute-agreement, 2-way mixed effects model [13]. A Chi-squared test was performed to evaluate the association between the apex side of scoliosis and handedness, upper limb function asymmetry, and PO. Statistical tests for ICCs, patient's demographics, clinical characteristics, and factors affecting the apex side of scoliosis were performed using SPSS (ver. 21.0; SPSS, Chicago, 
IL, USA). To assess the progression of scoliosis as measured by Cobb angle with age, we used a linear mixed-effects model (LMM) with a restricted maximum likelihood method for parameter estimation, with random intercept and slope with the possible correlation between them. Each factor affecting the progression of scoliosis (PO, GMFCS level, lumbar lordosis, vertebral rotation, sex, and history of epilepsy) was considered a fixed effect, and each patient was considered a random effect. Statistical tests for factors affecting the progression of scoliosis were performed using MATLAB Release 2021a and Statistic and Machine Learning Toolbox (MathWorks, Natick, MA, USA). $p$ values less than 0.05 were considered statistically significant.

\section{Results}

The patient's demographics and clinical characteristics are shown in Table 1. Fifty-five patients $(47.4 \%)$ were female. The patient's median (interquartile range) age at the initial evaluation was 3.1 (1.7-5.9) years, and at the last assessment was 18.05 (11.34-21.91) years. The median (interquartile range) duration of the interval between each radiograph was 1.11 $(0.75-1.91)$ years, and the period between initial and last radiographs was 5.0 (2.6-8.4) years. The number (percentage) of patients over 18 years of age at the initial evaluation was zero $(0 \%)$ and at the last assessment was five (4.31\%). Cobb angle greater than $10^{\circ}$ was observed in 45 patients $(38.79 \%)$ at the initial evaluation and 68 patients $(58.62 \%)$ at the last evaluation. Most of the patients had cerebral palsy $(107,92.2 \%)$, and others had brain neoplasm (2), Fukuyama muscular dystrophy (1), spinal muscular atrophy (1), mitochondrial diseases (1), Rett syndrome (1), Lesch Nyhan syndrome (1), Dandy-Walker syndrome (1), and Noonan syndrome (1). During the follow-up period, two patients applied thoraco-lumbo-sacral braces, thirty-seven non-ambulatory patients used seating system, and seven patients underwent hip joint surgery due to hip dislocation (five bilaterally, two left side).

Table 1. Participants' demographic data.

\begin{tabular}{|c|c|}
\hline Parameter & Value, N (Range or \%) \\
\hline Subjects & 116 \\
\hline Female & $55(47.4)$ \\
\hline Age at the first radiograph (years) ${ }^{1}$ & $3.1(1.7-5.9)$ \\
\hline Age at the last radiograph (years) ${ }^{1}$ & $18.05(11.34-21.91)$ \\
\hline Interval between each radiograph (years) ${ }^{1}$ & $1.11(0.75-1.91)$ \\
\hline Period between initial and last radiographs (years) ${ }^{1}$ & $5.0(2.6-8.4)$ \\
\hline Handedness, right/left/unknown & $38 / 34 / 44(32.8 / 29.3 / 38.0)$ \\
\hline Functional asymmetry of upper limbs, yes/no/unknown & $56 / 47 / 13(48.3 / 40.5 / 11.2)$ \\
\hline $\begin{array}{l}\text { Presence of epilepsy } \\
\text { GMFCS }{ }^{2} \text { level }\end{array}$ & $51(44.0)$ \\
\hline I & $7(6.4)$ \\
\hline II & $14(12.7)$ \\
\hline III & $6(5.5)$ \\
\hline IV & $37(33.6)$ \\
\hline $\mathrm{V}$ & $46(41.8)$ \\
\hline
\end{tabular}

${ }^{1}$ Median (interquartile range), ${ }^{2}$ GMFCS; gross motor function classification system.

Inter-rater reliability of the measurements is described in Table 2, with good reliability for $\mathrm{PO}$ and vertebral rotation and excellent reliability for scoliosis Cobb angle and lumbar lordosis angle [13]. The difference in mean angle of scoliosis, PO, and lumbar lordosis between the two inspectors were $3.88,2.42$, and 7.78 degrees, respectively. 
Table 2. Inter-rater reliability of radiographic measurements.

\begin{tabular}{ccc}
\hline Measurements & ICC $^{\mathbf{1}}$ & $\mathbf{9 5 \%}^{\mathbf{2} \mathbf{C I}^{\mathbf{2}}}$ \\
\hline Scoliosis Cobb angle $\left(^{\circ}\right)$ & 0.955 & $0.945-0.964$ \\
Pelvic obliquity $\left(^{\circ}\right)$ & 0.840 & $0.804-0.870$ \\
Lumbar lordosis angle $\left(^{\circ}\right)$ & 0.929 & $0.906-0.945$ \\
Vertebral rotation (Nash-Moe grade) & 0.807 & $0.755-0.847$ \\
\hline
\end{tabular}

${ }^{1}$ ICC; interclass correlation coefficient, ${ }^{2} \mathrm{CI}=$ confidence interval.

\subsection{Factors Affecting the Progression of Scoliosis}

Figure 2 shows the subject-specific profiles and estimated annual change of Cobb angle according to each factor ( $\mathrm{PO}$, gross motor function, lumbar lordosis, vertebral rotation, sex, and epilepsy). PO greater than $2.5^{\circ}$, GMFCS level V, the presence of vertebral rotation (Nash-Moe grade $\geq 1$ ), female sex were significant predictors of the progression of the scoliosis curve ( $p=0.04,<0.001,<0.001,0.005$, respectively). Reduced lumbar lordosis (less than $18^{\circ}$ ) at or more than two years of age and the presence of epilepsy did not significantly contribute to the progression of scoliosis ( $p>0.05$ in both). A value that is two standard deviations lower than the average value of typically developing children aged 2-4 years reported in the previous study was used as the reference for reduced lumbar lordosis [14].
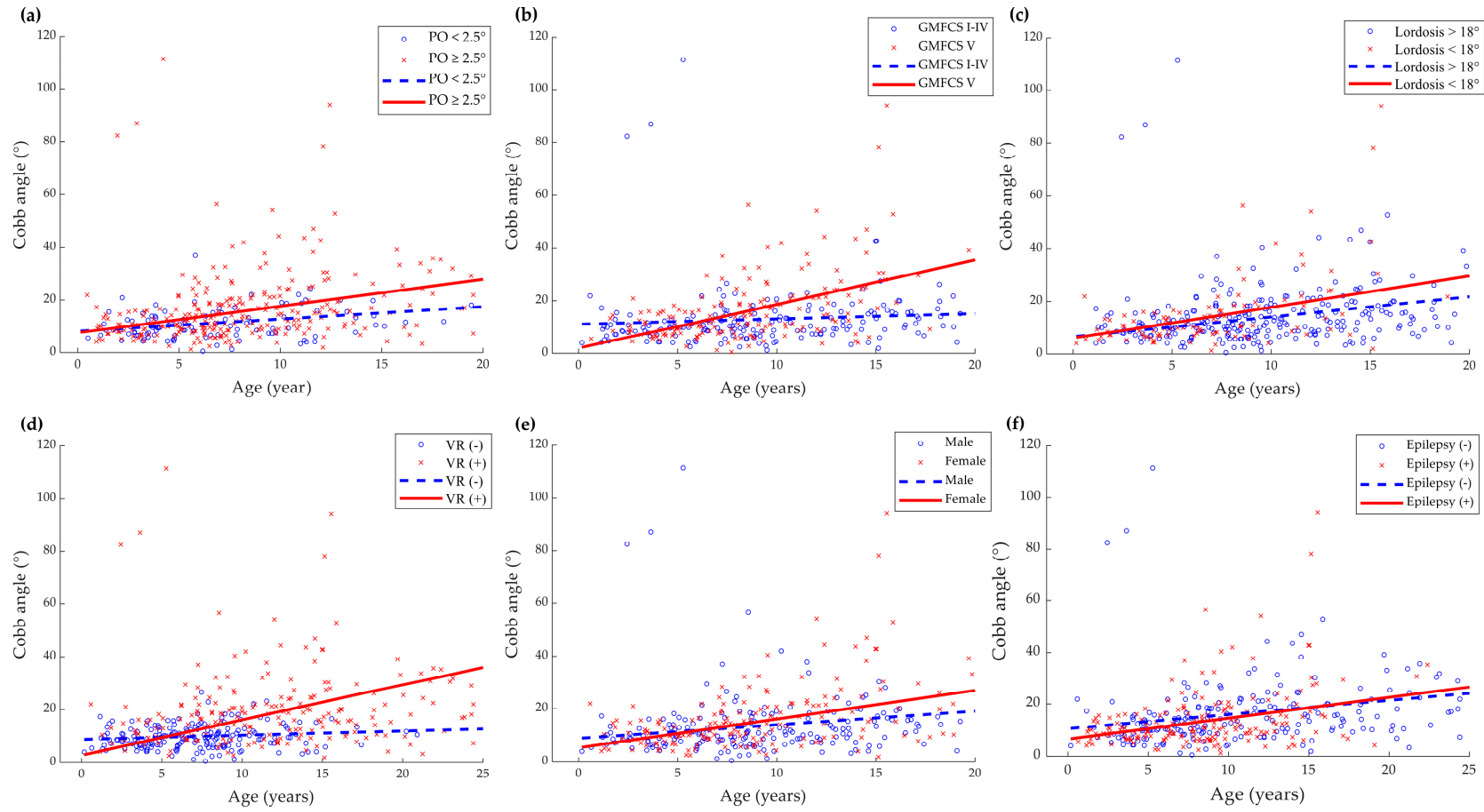

Figure 2. Subject-specific (scatterplot) and predicted progression line of Cobb angle $\left(^{\circ}\right.$ ) versus age (years) according to clinical parameters: (a) pelvic obliquity (PO); (b) gross motor function classification system (GMFCS); (c) lumbar lordosis; (d) vertebral rotation (VR); (e) sex; (f) epilepsy. There was a significant increase in the progression rate of scoliosis in patients with $\mathrm{PO} \geq 2.5^{\circ}$, GMFCS level V, vertebral rotation (Nash-Moe grade $\geq 1$ ), and in female patients. Reduced lumbar lordosis $\left(<18^{\circ}\right)$ in $\geq 2$ years of age and the presence of epilepsy did not significantly affect scoliosis progression.

\subsection{Factors Affecting the Apex Side of Scoliosis}

The effects of handedness and asymmetric upper limb function were analyzed in 82 patients with a Cobb angle of 10 degrees or more based on the final radiograph of each patient. Among them, the effect of $\mathrm{PO}$ was analyzed in 58 patients with 2.5 or more degrees of PO. The Chi-square test (Table 3) revealed that functional asymmetricity of upper limbs and handedness was not significantly associated with the apex side of scoliosis $\left(\chi^{2}=1.87\right.$ 
and 4.21, respectively, $p>0.05)$. However, in patients with $\mathrm{PO} \geq 2.5^{\circ}$, there was a significant correlation between the higher side of the PO and the apex side of the scoliosis $\left(\chi^{2}=12.91\right.$, $p<0.001)$. The proportion of patients with apex side of scoliosis opposite to the high side of $\mathrm{PO}$ was $75.0 \%$ (43/58). Subgroup analysis was performed to investigate the correlation between the secondary curve apex and the higher side of PO. The secondary curve was at the lumbar level in six out of fifty-eight patients and at the thoracic level in ten patients. In the group with the secondary curve at the thoracic level, the higher side of $\mathrm{PO}$ was located on the opposite side of the major curve apex in eight out of ten patients $(80.0 \%)$, but in the group with the secondary curve at the lumbar level, one out of six patients $(16.7 \%)$, the higher side of $\mathrm{PO}$ was located on the opposite side of the major curve apex. Though it was difficult to confirm the statistical significance due to the small number of patients, the presence of secondary curve at the lumbar level tended to show additional associations with the higher side of $\mathrm{PO}$.

Table 3. The direction of apex of scoliosis and clinical parameters (functional asymmetry of upper limbs, handedness, and higher side of pelvic obliquity).

\begin{tabular}{|c|c|c|c|c|c|}
\hline & & \multicolumn{3}{|c|}{ Apex of Scoliosis, N (\%) } & \multirow{2}{*}{$p$ Value } \\
\hline & & Right & Left & Total & \\
\hline \multirow{3}{*}{$\begin{array}{c}\text { Functional } \\
\text { asymmetry of upper } \\
\text { limbs }\end{array}$} & Yes & $13(33.3)$ & $26(66.7)$ & $39(100.0)$ & \multirow{3}{*}{0.39} \\
\hline & No & $14(43.8)$ & $18(56.3)$ & $32(100.0)$ & \\
\hline & Unknown & $6(54.5)$ & $5(45.5)$ & $11(100.0)$ & \\
\hline \multirow{3}{*}{ Handedness } & Right & $6(54.5)$ & $5(45.5)$ & $11(100.0)$ & \multirow{3}{*}{0.12} \\
\hline & Left & $13(41.9)$ & $18(58.1)$ & $31(100.0)$ & \\
\hline & Unknown & $4(21.1)$ & $15(78.9)$ & $19(100.0)$ & \\
\hline \multirow{2}{*}{$\begin{array}{l}\text { Higher side of pelvic } \\
\text { obliquity }\end{array}$} & Right & $13(28.9)$ & $32(71.1)$ & $45(100.0)$ & \multirow{2}{*}{$<0.001$ * } \\
\hline & Left & $11(84.6)$ & $2(15.4)$ & $13(100.0)$ & \\
\hline
\end{tabular}

* Significant correlation $(p<0.05)$.

\section{Discussion}

Among spinal deformity, adolescent idiopathic scoliosis is the most common deformity, occurring in healthy children around puberty and progressing with skeletal growth. In patients with a curve of less than $30^{\circ}$ after bone maturation, scoliosis rarely progresses, and in the case of $30^{\circ}$ to $50^{\circ}$, an average of $10^{\circ}$ to $15^{\circ}$ progresses throughout lifetime [15]. On the other hand, neuromuscular scoliosis can occur even before puberty, and in previous study, there was no significant decrease in the progression of scoliosis after growth maturation, and the Cobb angle could continuously increase [2]. Saito et al. [16] observed that 11 out of $13(85 \%)$ had a spinal curve of $40^{\circ}$ or more at the age of 15 , and as a result, the curvature progressed to more than $60^{\circ}$ in patients with cerebral palsy. According to the aggressive nature of the progression, neuromuscular scoliosis causes more physiologic impairment affecting gait, sitting posture, pain, and decreased cardiopulmonary function than adolescent idiopathic scoliosis.

In this study, we found that increased PO, severe motor dysfunction (GMFCS level V), vertebral rotation, and female sex were contributing to the progression of scoliosis with age. In general, an ambulatory function is known as a critical factor for scoliosis [17]. Several investigators have identified GMFCS as a decisive factor influencing scoliosis progression, which supports our results. Lee et al. [18] estimated the annual changes in radiographic indices of the spine in 184 patients with $\mathrm{CP}$ and found that the annual increase in scoliosis Cobb angle was higher in the GMFCS Level IV-V group than in the GMFCS Level I-II and III groups. Garg et al. [19] analyzed the difference in scoliosis progression according to GMFCS level in $115 \mathrm{CP}$ patients who underwent varus derotational osteotomy surgery. The authors reported that the annual progression in the GMFCS I-III and IV groups was $1^{\circ}-2^{\circ}$ degrees, but in the GMFCS V group, the annual progression was $3.5^{\circ}$, showing more rapid progression. Similar results were obtained in this study as well. With the analysis by 
GMFCS level, there was no significant difference in GMFCS Level I-IV. However, the slope in Cobb angle in GMFCS Level V was significantly different from other levels.

Previous researchers have investigated the association between coronal spine deformities and PO in scoliosis $[5,19]$. Biomechanically, the pelvis serves as an important pivot between the trunk and lower extremities, playing a fundamental role in maintaining an unsupported sitting posture and ambulation [20]. Therefore, the progression of scoliosis with $\mathrm{PO}$ and the loss of the sitting balance are common features in severely affected patients with neurological disorders. A recent study reported that the progression of scoliosis, PO, and hip subluxation were related to each other in non-ambulatory patients with neuromuscular disorders, however, the sequence of development was difficult to determine [21]. Generally, PO more than 5 degrees is regarded as significant; however, even 2.5 degrees of $\mathrm{PO}$ was revealed to be significantly related with the progression of Cobb angle in this study. Further studies are needed on the biomechanical role of $\mathrm{PO}$ and the sequence of structural alterations in the hip, pelvis, and spine.

Vertebral rotation is an essential component of scoliosis from a three-dimensional perspective. Mohanty et al. [22] analyzed 158 patients with adolescent idiopathic scoliosis and revealed a significant association between Cobb angle and Nash-Moe grade. Evidence for the role of vertebral rotation in scoliosis is limited. Although the presence of vertebral rotation had a significant effect on the progression of scoliosis in our results, the effect of the degree of rotation could not be confirmed as the number of patients with Grade 2 or higher vertebral rotation in the Nash-Moe grade was small.

Female sex is known to be a factor influencing the progression of the curve in adolescent idiopathic scoliosis [15]. In the result of our study, the slope of the trend line was significantly larger in girls, showing a similar trend as in idiopathic scoliosis. In patients with neurological disorders, the female sex has been suggested to increase the risk of developing scoliosis, and the odds ratio for females was 1.9 compared to males $[23,24]$. However, for the progression of scoliosis, sex did not have a significant effect in the previous study [18], further research involving a large sample size is required.

Previous studies have also suggested the relationship between the development of scoliosis and epilepsy [23,24]; however, no significant effect on progression was identified in our result. Whether epilepsy itself is a risk factor for scoliosis or whether children with epilepsy tend to have more severe functional disabilities is unclear. Moreover, the effect of epilepsy on the progression of scoliosis is inconclusive.

A secondary analysis of the factors determining the apex side of scoliosis demonstrated that $\mathrm{PO}$ was a significant factor; however, handedness or asymmetric upper limb function had no significant effect on the direction of scoliosis. The current results were consistent with the previous reports that $89 \%$ of the patients with CP had the convexity of scoliosis on the opposite side of the high side of the PO [5]. We additionally found that this tendency was offset in the case of patient whose secondary curve was at the lumbar level. In conclusion, pelvis is thought to serve as a critical bone that determines the direction and influence the progression of the scoliotic curve.

A limitation of our study is that since all data were collected retrospectively, an unequal number of radiographs were collected for each subject at non-fixed time points. However, to compensate for this problem, we used the LMM to determine whether each variable significantly influenced the trend of changes in Cobb angle with time [25]. Second, we did not measure the location or type of scoliotic curvature, the severity of hip subluxation or hip dislocation, history of hip surgery, or decreased range of hip and knee joints motion. These may be another possible factor influencing scoliosis progression, and further studies including these factors are needed. Third, since the data were collected in rehabilitation clinic, the severity of scoliosis tends to be milder than that of other studies, even with severe gross motor function. Children with more severe scoliosis were referred to an orthopedic surgeon and thereafter were not included in this data. In addition, many of them are receiving rehabilitation therapy and may be a group with a high level of interest from the caregiver. Forth, the median duration of follow-up was 5 years, which may 
miss the progressive stage of scoliosis in some patients. Fifth, Rett syndrome and Lesch Nyhan syndrome are gender-specific syndromes involving female and male, respectively. However, only one patient for each syndrome was included in this study, which may have negligible impact on the analysis of gender effects on scoliosis progression. Lastly, GMFCS was applied to measure the gross motor function of all children including patients other than CP. Although GMFCS has been validated for children with CP and Down syndrome, it has been widely used to measure gross motor function in children with motor difficulties [26,27].

Various conservative treatments have been tried to prevent the progression of scoliosis in patients with neurological disorders. Physiotherapy and spinal orthoses are helpful for muscle balance, postural support, and prevention of contractures but are known to have a limited role in decreasing curve progression $[28,29]$. An intensive pharmacological method such as an intrathecal baclofen pump was revealed not to change the progression of scoliosis with CP [30]. Although observation and non-surgical treatment are recommended when the curve is less than 40 degrees, most scoliosis results in spinal instrumentation and fusion due to significant curve progression, loss of sitting balance, and function [31]. By identifying the factors that influence the progression and apex direction of scoliosis, patients at high risk could be more actively intervened, such as shortening the follow-up period or preemptively referring to a surgeon. Future research that proposes predictive algorithms for scoliosis progression and provides criteria for distinguishing groups that require active intervention is needed to use medical resources more efficiently while benefiting patients.

\section{Conclusions}

Our results indicated that PO, GMFCS Level V, vertebral rotation, and female sex were important factors affecting the progression of scoliosis. Underdevelopment of lumbar lordosis and epilepsy had no significant effect on the progression of scoliosis. In addition, there was a significant association with $\mathrm{PO}$ and scoliosis curve direction, with the higher side of $\mathrm{PO}$ was opposite to the apex side of scoliosis. However, asymmetric upper limb function or handedness did not affect the direction of scoliosis. The factors identified in our study can be used for further studies on the predictive model of scoliosis progression in patients with neurological disorders.

Author Contributions: Conceptualization, B.-Y.H.; methodology, B.-Y.H., Y.H. and Y.-J.Y.; validation, Y.-J.Y. and B.-Y.H.; formal analysis, B.-Y.H., Y.H. and Y.-J.Y.; investigation, J.-G.P., L.J. and Y.-J.Y.; data curation, J.-G.P., L.J., Y.-J.Y., M.-J.Y. and B.-Y.H.; writing-original draft preparation, J.-G.P. and Y.-J.Y.; writing-review and editing, Y.-J.Y. and B.-Y.H.; visualization, Y.-J.Y.; supervision, S.L. and J.-S.K.; project administration, B.-Y.H. All authors have read and agreed to the published version of the manuscript.

Funding: This research was not funded.

Institutional Review Board Statement: The study was conducted according to the guidelines of the Declaration of Helsinki and approved by the Institutional Review Board of Catholic University, College of Medicine (Registry No. VC20RISI0266).

Informed Consent Statement: Patient consent was waived because the research involves no more than minimal risk to the subjects.

Data Availability Statement: The data presented in this study are available on request from the corresponding author.

Conflicts of Interest: The authors declare no conflict of interest. 


\section{References}

1. Roberts, S.B.; Tsirikos, A.I. Factors influencing the evaluation and management of neuromuscular scoliosis: A review of the literature. J. Back Musculoskelet. Rehabil. 2016, 29, 613-623. [CrossRef] [PubMed]

2. Yoshida, K.; Kajiura, I.; Suzuki, T.; Kawabata, H. Natural history of scoliosis in cerebral palsy and risk factors for progression of scoliosis. J. Orthop. Sci. 2018, 23, 649-652. [CrossRef] [PubMed]

3. Loeters, M.J.; Maathuis, C.G.; Hadders-Algra, M. Risk factors for emergence and progression of scoliosis in children with severe cerebral palsy: A systematic review. Dev. Med. Child. Neurol. 2010, 52, 605-611. [CrossRef] [PubMed]

4. Gu, Y.; Shelton, J.E.; Ketchum, J.M.; Cifu, D.X.; Palmer, D.; Sparkman, A.; Jermer-Gu, M.K.; Mendigorin, M. Natural history of scoliosis in nonambulatory spastic tetraplegic cerebral palsy. PMER 2011, 3, 27-32.

5. Hagglund, G. Association between pelvic obliquity and scoliosis, hip displacement and asymmetric hip abduction in children with cerebral palsy: A cross-sectional registry study. BMC Musculoskelet. Disord. 2020, 21, 464. [CrossRef] [PubMed]

6. Porter, D.; Michael, S.; Kirkwood, C. Patterns of postural deformity in non-ambulant people with cerebral palsy: What is the relationship between the direction of scoliosis, direction of pelvic obliquity, direction of windswept hip deformity and side of hip dislocation? Clin. Rehabil. 2007, 21, 1087-1096. [CrossRef]

7. Palisano, R.J.; Rosenbaum, P.; Bartlett, D.; Livingston, M.H. Content validity of the expanded and revised Gross Motor Function Classification System. Dev. Med. Child. Neurol. 2008, 50, 744-750. [CrossRef]

8. Cobb, J. Outline for the study of scoliosis. Instr. Course Lect. AAOS 1948, 5, 261-275.

9. King, H.A.; Moe, J.H.; Bradford, D.S.; Winter, R.B. The selection of fusion levels in thoracic idiopathic scoliosis. J. Bone Jt. Surg. Am. 1983, 65, 1302-1313. [CrossRef]

10. Maloney, W.J.; Rinsky, L.A.; Gamble, J.G. Simultaneous correction of pelvic obliquity, frontal plane, and sagittal plane deformities in neuromuscular scoliosis using a unit rod with segmental sublaminar wires: A preliminary report. J. Pediatr. Orthop. 1990, 10, 742-749. [CrossRef]

11. Ames, C.P.; Smith, J.S.; Scheer, J.K.; Bess, S.; Bederman, S.S.; Deviren, V.; Lafage, V.; Schwab, F.; Shaffrey, C.I. Impact of spinopelvic alignment on decision making in deformity surgery in adults: A review. J. Neurosurg. Spine 2012, 16, 547-564. [CrossRef] [PubMed]

12. Nash, C.; Moe, J.H. A study of vertebral rotation. J. Bone Jt. Surg Am. 1969, 51, 223-229. [CrossRef]

13. Koo, T.K.; Li, M.Y. A Guideline of Selecting and Reporting Intraclass Correlation Coefficients for Reliability Research. J. Chiropr. Med. 2016, 15, 155-163. [CrossRef]

14. Shefi, S.; Soudack, M.; Konen, E.; Been, E. Development of the lumbar lordotic curvature in children from age 2 to 20 years. Spine (Phila Pa 1976) 2013, 38, E602-E608. [CrossRef]

15. Reamy, B.V.; Slakey, J. Adolescent idiopathic scoliosis: Review and current concepts. Am. Fam. Physician 2001, 64, 111-116.

16. Saito, N.; Ebara, S.; Ohotsuka, K.; Kumeta, H.; Takaoka, K. Natural history of scoliosis in spastic cerebral palsy. Lancet 1998, 351, 1687-1692. [CrossRef]

17. Allam, A.M.; Schwabe, A.L. Neuromuscular scoliosis. PMER 2013, 5, 957-963.

18. Lee, S.Y.; Chung, C.Y.; Lee, K.M.; Kwon, S.S.; Cho, K.J.; Park, M.S. Annual changes in radiographic indices of the spine in cerebral palsy patients. Eur. Spine J. 2016, 25, 679-686. [CrossRef]

19. Garg, S.; Engelman, G.; Yoshihara, H.; McNair, B.; Chang, F. The Relationship of Gross Motor Functional Classification Scale Level and Hip Dysplasia on the Pattern and Progression of Scoliosis in Children with Cerebral Palsy. Spine Deform. 2013, 1, $266-271$. [CrossRef]

20. Hasler, C.; Brunner, R.; Grundshtein, A.; Ovadia, D. Spine deformities in patients with cerebral palsy; the role of the pelvis. J. Child. Orthop. 2020, 14, 9-16. [CrossRef]

21. Patel, J.; Shapiro, F. Simultaneous progression patterns of scoliosis, pelvic obliquity, and hip subluxation/dislocation in nonambulatory neuromuscular patients: An approach to deformity documentation. J. Child. Orthop. 2015, 9, 345-356. [CrossRef] [PubMed]

22. Mohanty, S.P.; Pai Kanhangad, M.; Gullia, A. Curve severity and apical vertebral rotation and their association with curve flexibility in adolescent idiopathic scoliosis. Musculoskelet. Surg. 2021, 105, 303-308. [CrossRef]

23. Bertoncelli, C.M.; Bertoncelli, D.; Elbaum, L.; Latalski, M.; Altamura, P.; Musoff, C.; Rampal, V.; Solla, F. Validation of a Clinical Prediction Model for the Development of Neuromuscular Scoliosis: A Multinational Study. Pediatr. Neurol. 2018, 79, 14-20. [CrossRef] [PubMed]

24. Pettersson, K.; Wagner, P.; Rodby-Bousquet, E. Development of a risk score for scoliosis in children with cerebral palsy. Acta Orthop. 2020, 91, 203-208. [CrossRef]

25. Nguyen, D.V.; Senturk, D.; Carroll, R.J. Covariate-Adjusted Linear Mixed Effects Model with an Application to Longitudinal Data. J. Nonparametr Stat. 2008, 20, 459-481. [CrossRef]

26. Ruck-Gibis, J.; Plotkin, H.; Hanley, J.; Wood-Dauphinee, S. Reliability of the gross motor function measure for children with osteogenesis imperfecta. Pediatr. Phys. Ther. 2001, 13, 10-17. [CrossRef]

27. Wright, M.J.; Halton, J.M.; Martin, R.F.; Barr, R.D. Long-term gross motor performance following treatment for acute lymphoblastic leukemia. Med. Pediatr. Oncol. Off. J. SIOP_Int. Soc. Pediatr. Oncol. (Soc. Int. D'oncologie Pédiatrique 1998, 31, 86-90. [CrossRef]

28. Miller, A.; Temple, T.; Miller, F. Impact of orthoses on the rate of scoliosis progression in children with cerebral palsy. J. Pediatr. Orthop. 1996, 16, 332-335. [CrossRef] 
29. Shakil, H.; Iqbal, Z.A.; Al-Ghadir, A.H. Scoliosis: Review of types of curves, etiological theories and conservative treatment. J. Back Musculoskelet. Rehabil. 2014, 27, 111-115. [CrossRef] [PubMed]

30. Shilt, J.S.; Lai, L.P.; Cabrera, M.N.; Frino, J.; Smith, B.P. The impact of intrathecal baclofen on the natural history of scoliosis in cerebral palsy. J. Pediatr. Orthop. 2008, 28, 684-687. [CrossRef] [PubMed]

31. Jones-Quaidoo, S.M.; Yang, S.; Arlet, V. Surgical management of spinal deformities in cerebral palsy. A review. J. Neurosurg. Spine 2010, 13, 672-685. [CrossRef] [PubMed] 